\title{
LOS ESCENARIOS DE LAS LEYENDAS BECQUERIANAS
}

\author{
El romanticismo de Bécquer
}

En muchas de sus leyendas, entre las que se cuentan, sin duda, las más características, Bécquer, que es cronológicamente un posromántico, se muestra cargado de elementos estéticos propios del romanticismo, especialmente en cuanto hace referencia al escenario: ruinas, nocturno, lluvia, relámpagos, truenos, soledad, vejez, espectros, misterio, irrealidad, melancolia, tencbrismo, brumas, silencios cargados de un latente más allá, presencias invisibles, vaguedad, consideración subjetiva de la Naturaleza... Pero no sólo en lo que se refiere a los escenarios y ambientes. En nuestra obra Mundo y trasmundo de las lcyendas de Bécquer ${ }^{1}$, mostramos otros caracteres, ajenos a este aspecto, que por si solos bastan y sobran para poder afirmar, como lo hace Allison Peers, que, aunque el verdadero romanticismo, es decir, el romanticismo considerado como escuela y no como una constante de la forma de sentir lo literario algunos escritores - casi todos los espanoles, al decir de este autor-, aunque el verdadero romanticismo, íbamos a decir, sólo tuvo "forma netamente definida o vida corporativa" en el decenio comprendido entre El moro expósito y Don Juan Tenorio, "con Bécquer murió, en I870, un poeta puramente romántico" ${ }^{2}$.

Sobre este punto, sin embargo, la opinión no es unánime. Casalduero, por ejemplo, aun reconociendo que el romanticismo, desaparecido ya hacia 1845 , deja una huella perceptible durante todo el siglo $x I x, y^{\prime}$ aceptando el uso vulgar de la palabra romántico, "tanto para calificar a una muchacha soñadora o a un joven melancólico como a un poeta que hable de amor, lo que acontece con Bécquer», considera desorienta-

- Madrid, Gredos 1070. V. capitulo titulado La misica de los arcangeles.

2 V. Li. Ar,ISON P'Hirs, Historia del movimiento romántico español. Mladrid, Gredos, r954, t. II, p. 399. 
dor que en las historias de la literatura española "todavía se sirvan de él no ya al estudiar a Zorrilla, sino al referirse a las Rimas, las Carlas desde mi celda y las Leyendas becquerianas" 1.

Dlez Taboada, en un estudio comparativo de ciertos aspectos de las obras de Espronceda y Bécquer, estima que a Bécquer se le viene considerando por más romántico de lo que en realidad, a su juicio, es ${ }^{2}$. Asegura, sin embargo, que este error en la consideración se refiere sólo al aspecto histórico, $y$, en otro lugar, reconoce que Gustavo Adolfo resulta ser uel representante del auténtico romanticismo español, porque en él se hace íntimo lo exótico, y lo nacional se sustituye por lo personal, y no sólo por lo social. Pero sobre todo porque en Bécquer los elementos narrativos y descriptivos del romanticismo, reestructurados con la más intima coherencia, fraguan en moldes líricos nuevos" ${ }^{3}$.

'Todo esto es cierto, como lo es también que en la obra de Bécquer se dan multitud de caracteres propios del romanticismo, si bien expresados, las más de las veces - y en ello radica la fascinación que para el gusto actual ejerce su personalidad literaria-, de una forma que preludia concepciones estéticas posteriores.

En este trabajo, en que nos vamos a ocupar del tratamiento del paisaje en las leyendas becquerianas, creemos que, al menos, parte de lo dicho va a quedar documentado con claridad. Comenzaremos por el examen de dos leyendas ejemplares al respecto: La Venta de los Gatos y La rosa de pasińn.

\section{"La Venta de los gatos"}

De las dos partes ell que con claridad se divide la trama de La Venta de los gatos, la primera está centrada en la idea de vida-amor-esperanza, y, la segunda, en la de muerte-dolor-desesperación. Una y otra nos las ofrece el autor a través del tratamiento del paisaje, que nos presenta como exterior, objetivo, en la primera, y con el que se funde cordialmente en la segunda. El resultado es, consiguiente y respectivamente, un jugoso, evocador fragmento de prosa costumbrista y un profundo poema en el que Gustavo Adolfo pulsa las más tensas e intensas cuerdas de su laúd. Para lograr aquél se limita propiamente a dar unas indicaciones

1 Cít. Johquín Casainuiaro, Espronceda, 2. ed. Madrid, Gredos, 1967. pp. 70 y 71 .

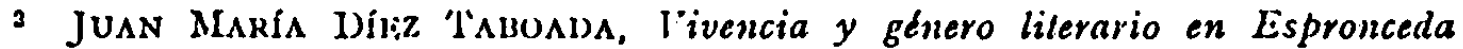
y Bicquer, en Homenujes. Estudios de Filologia Española. Madrid, 1964, p. 22.

- V. Junn maria dibz 'Manonda, La mujer ideal. Aspectos y fuentes de las vimas de Bécquer. Madrid, C. S. I. C., 1965, p. 7. 
al lector; para conseguir el segundo se nos ofrece en cucrpo y alma él mismo. En efecto: quiere comunicamos la sencilla belleza, el pintoresquismo, el bullicio, la alegría del lugar; pues bien, por una acumulación de elementos descriptivos, como en su prosa es habitual cuando se trata de comunicar no sentimientos $y$ emociones, sino acontecimientos ${ }^{\text {; }}$ elementos descriptivos, digo, sobriamente adjetivados o aún sin adjetivar, nos da las partes extemas del cuadro cuyo contenido pleno nosotros hemos de forjar en nuestra imaginación. Figuraos... Imaginaos... Figuraos... Comienzan cada uno de los períodos en los que Bécquer nos da el lugar, la gente del lugar y el tiempo en que tiene lugar la acción:

"I iguraos una casita blanca como el campo de la nicve, con su cubierta de tejas rojizas la una y verdinegras las otras, entre las cuales crece un sinfin cle jaraunagos y matas de reseda. Un cobertizo de madera baña en sombras el dintel de la puerta a cuyos lados hay dos poyos de ladrillos $y$ argamasa. Iimpolradas en el muro, que rompen varios ventanillos abiertos a capriclio para dar luz al interior. y de los cuales unos son más bajos y otros más altos, éste en forma cuadrangular, aquél imitando un ajimez o una claraboya, se ven de trecho en trecho algunas estacas y anillas de hicro que sirven para atar las caballerias. Una parra añosisima, que retucrce sus negruzcos troncos por cutre la armazón de uadera que la sostiene, vistiéndose de pámpanos y hojas verdes y anchas, cubre como un dosel el estrado, el cual lo componen tres bancos de pino, media docena de sillas de anca desvencijadas y liasta seis o siete mesas cojas y liechas de tablas mal unidas. Por uno de los costados de la casa sube una madreselva, agarráudose a las grietas de las paredes, liasta llegar al tejado, de cuyo alero peuden algunas gulas que se mecen en el aire, asemejando flotantes pabellones de verdura. $A 1$ pie del tronco corre una cerca de cañizos, señalando los limites de un pequeño jardin. que parece una canustilla de juucos rebosando flores. I as copas de dos corpulentos árboles que se levantan a espaldas del ventorrillo forman el fondo oscuro sobre el cual se destacan sus blancas chimeneas, completando la decoración los vallados de las huertas, llenos de pitas y de zarzamoras; los retamares que crecen a la orilla del agua y el Guadalquivir, que se aleja arrastrando con lentitud su torcida corriente por entre aquellas agrestes márgenes, hasta llegar al pie del antiguo convento de San Jerónimo, el cual se asoma por cima de los espesos olivares que lo rodean y dibuja por oscuro la negra silucta de sus torres sobre un cielo azul transparente.

Imaginaos este paisaje animado por una multitud de figuras de hombres, mujeres, chiquillos y animales formando grupos a cual más pintorescos y característicos; aqui el ventero, rechoncho y coloradote, sentado al sol en una silleta baja, deshaciendo entre las manos el tabaco para liar un cigarrillo y con el papel en la boca; all un regatón de la Macarena, que canta entornando los ojos y acompañándose con una guitarrilla, mientras otros le llevan el compás con las palmas

1 Cfr., por ejemplo, la descripción del sarao eu El Cristo de la Calavera, O. C. 'l. I., p. 20 I y ss. Citamos por la edición -segunda- de M. SAnMisuer, para $\Lambda$ frodisio $\Lambda$ guado, Madrid, 1949. Un comentario a dicha descripción puede verse en el capitulo Autobiografia en las leyendas, de uuestra obra ya citada. 
o golpeando las mesas con los vasos; más allá una turba de muchachas con su paũuelo de espumilla de mil colores y toda una maceta de claveles en el pelo que tocan la pandereta, y chillan, y rien, y hablan a voces en tanto que inpulsan como locas el columpio colgado entre dos árboles; y los mozos del ventorrillo que van y vienen con bateas de manzanilla y platos de aceitunas; y las bandas de gentes del pueblo que hormiguean en el camino; dos borrachos que disputan con un majo que requiebra al pasar a una buena moza; un gallo que cacarea esponjáudose orgulloso sobre las bardas del corral; un perro que ladra a los chiquillos que le hostigan con palos y piedras; el aceite que hierve y salta en la sartén donde frlen el pescado; el chasquear de los látigos de los caleseros que llegan levantando una nube de polvo; ruido de cantates, de castañuelas, de risas, de voces, de silbidos y de guitarras; y golpes en las mesas, y palmadas, y estallidos de jarros que se rompen; $y$ mil y mil rumores extraños y discorcles que forman una alegre algarabia imposible de describir. Figuraos todo esto en una tarde templada y serena, en la tarde de wno de los dias mís hermosos de Andalucia, donde tan liermosos sou siempre, y tendréis una idea del espectículo que se ofreció a mis ojos la primera vez que, guiado por su fama, fui a visitar aquel célebre ventorrillow 1 .

Ińn la segunda descripción, en cambio, el escenario nos es ofrecido a través de su estado de ánimo. Iistado de ánimo a la vez provocado en él por los cambios sustanciales que ya sabe que se han producido en el paisaje.

- Bien fuese que la tarde estaba un poco encapotada, bien que la disposición de mi ánino me inclinaba a las ideas melancólicas, lo cierto es que sentl frio y tristeza y noté un silencio que we recordaba la completa soledad, como el sueño recuerda la muerte" 2 .

lividentemente, se trata ya arjuí de un recurso estético y no de la deposición de un testigo. Lil paisaje ha asumido un papel pasivo (en la primera parte era activo; con sus colores, su luz, influía en el autor y en sus personajes): recibe el color, la luz, la configuración de los acontecimientos, los sentimientos. Ahora faltan en ella «los tonos calurosos y armónicos»; falta "frescura en la arboleda, ambiente en el espacio y luz en el terreno». Un paisaje "monótono", lleno de "figuras negras y aisladas». Y ello porque en el camino por el que pasan los muertos «hasta los árboles y las hierbas toman al cabo un color diferente».

"l'or aqui, un carro que pasa pausadamente, cubierto de luto, sin levantar polvo, sin cliasquido de látigo, sin algazara, sin movimiento casi; más allá, un hombre de mala catadura con un azadón en el hombro, o un sacerdote con el híbito talar y oscuro, o un grupo de ancianos mal vestidos o de aspecto repugnante, con cirios apagados en las manos, que volvian silenciosos, con la cabeza baja

1 Cfr. O. C. 'T. I, 1). 373-375.

2 Ibid., p. 384 . 
y los ojos fijos en la ticrra. Yo me crela transportado no sé adónde, pues todo lo que vela me recordaba un paisaje cuyos contornos cran los mismos de sicmpre, pero cuyos colores se hablan borrado, por decirlo ast, no quedando de ellos sino una media tinta dudosa. La impresión que experimentaba sólo puede compararse a la que sentimos en esos sueños en que, por un fenóneno inexplicable, las cosas son y no son a la vez, y los sitios en que crecmos hallarmos se transforman eu parte de una manera estrambótica e inposible.

Por últino, llegué al ventorrillo; lo recordé más por el rótulo, que aún conserva escrito con grandes letras en una de sus paredes, que por nada; pues en cuanto al caserio, se me figuró que hasta habia cambiado de formas y proporciones. Desde luego, puedo asegurar que estaba mucho mús ruinoso, abandonado y triste. La sombra del cementerio, que se alzaba en el fondo, parecia extenderse hacia él. envolviéndole en una oscura proyección, como en un sudario. Lil ventero estaba solo, completamente solon'.

$\mathrm{Y}$ se trata todavía de un paisaje tocado únicamente por la presencia agorera de la muerte. Los tonos se ensombrecen todavía más cuando el paisaje se impregna de la tragedia que ya no es potencial, que ya se levanta sobre la soledad, el silencio y el frío, encarnada en la ausencia de la muchacha, el dolor del ventero, la locura del hijo y la melancolía del poeta:

- I a noche comcnzaba a cerrar, oscura y tristisima. Iil ciclo estaba negro, y el campo, lo mismo. De los brazos de los árboles pendia aún, medio podrida, la soga del columpio agitada por el aire. Ne pareció la cuerda de una horca oscilando todavia después de haber descolgado a un reo. Sólo llegaban a mis oídos algunos rumores confusos: cl ladrido lejano de los perros de las huertas, el chirrido de una noria, largo, quejumbroso y agudo como un lanento; las palabras sucltas y horribles de los sepultureros, que concertaban en voz baja un robo sacrilego....2

La imaginación plástica de Bécquer sabe buscar el contraste del paisaje que simboliza la alegría y la felicidad con aquel que refleja la tristeza y la tragedia, a base de la transfurmación de los mismos elementos sobre los que antes nos ha llamado la atención. Al día luminoso y alegre corresponde la noche oscura y tristísima. Al verde y el azul del campo y el cielo del paisaje primero, el negro del segundo. A los cantos, el rasguco de la guitarra y el vocerío juvenil, los rumores confusos sobre los que destaca el coloquio grave y único de unos sepultureros que conciertan nada menos que un robo sacrílego. Pero la imagen decisiva es la de esa cuerda del alegre columpio de antaño que pende medio podrida, agitada por el aire, como la cuerda de una horca que oscila todavía después de liaber sido descolgado un reo. Un John Ford o un Einsestein

1 Ibid., pp. 384 y 385.

2 Ibid., p. 388. 
no hubieran hallado una imagen mejor para expresar el cambio producido en el ventorro.

\section{"La rosa de pasión»}

También en La rosa de pasión lleva a cabo Bécquer la fusión plena, por vía simbólica, del escenario con los personajes y la acción. IEjemplo de lo primero es la descripción de la casucha de Daniel. Dentro de aquel sucio antro, lóbrego y sombrío, la belleza de Sara resplandece como una flor entre hierbajos; entre la mezquindad y el rencor, la pureza de su espíritu brilla como una luz. Bien, pues este resplandor, este brillo, los simboliza Bécquer en la planta trepadora que, desde el tenducho, asciende jugosa y soberana hasta la parte de la casa en que ella habita.

'Sobre la puerta de la casucha del judio y dentro de un marco de azulejos de vivos colores, se abria un ajinez árabe, resto de las antiguas construcciones de los moros toledanos. Alredeclor de las caladas franjas del ajimez, y euredándose por la columuilla de mármol que lo partía en dos huecos iguales, subla desde el interior de la vivienda una de esas plantas trepadoras que se mecen verdes y llenas de savia y lozinia sobre los ennegrecidos nuros de los edificios ruinosost ${ }^{1}$.

Ejemplo de lo segundo es la descripción de la noche del sacrificio. Era noche de Viernes Santo y los habitantes de Toledo, después de haber asistido en la catedral al oficio de tinieblas, acababan de entregarse al sueño o se referían consejas al amor de la lumbre.

-Reinaba en la ciudad un silencio profundo, interrumpido a intervalos ya por las lejanas voces de los guardias nocturnos que en aquella época velaban en derredor del alcázar; ya por los gemidos del viento, que haclan girar las veletas de las torres, o zumbaba entre las torcidas revueltas de las calles, cuando el dueño de un barquichuelo que se mecia amarrado a un poste cerca de los molinos, que parecen como incrustados al pie de las rocas que baña el Tajo, y sobre las que se asienta la ciudad, vio aproximarse a la orilla, bajando trabajosamente por uno de los estrechos senderos que desde lo alto de los muros conducen al rio, una persona que al parecer agutardaba con impaciencian?.

Para la escena final, el escritor elige "los ruinosos restos de una iglesia bizantina, anterior a la conquista de los árabes", que se hallan en las afueras.

1 Ibidl., 1. 2.16 .

2 Ibid., p. 250. 
- En el atrio que dibujaban algunos pedruscos diseminados por el suelo, crecian zarzales y hicrbas parásitas, entre los que yacha meclio oculto, ya el destrozado capitel de una columna, ya un sillar groscramente esculpido con hojas entrelazadas, endriagos horribles o grotescas e informes figuras humanas. Del templo sólo quedaban en pic los muros laterales y algumos arcos rotos y cubiertos de hiedran" 1.

\section{Un elemento del paisaje tomántico: las ruinas}

Cualquiera que esté familiarizado con la obra en prosa de Bécquer sabe de su afición a los cementerios, a las ruinas y a todo lo que simbolice o represente la belleza que se marchita. Iay muchos más pasajes en las leyendas dedicados a la decadencia de la luz -crepúsculos, atardeceres melancólicos, anocheceres- que a la plenitud del mediodía; muchos más destinados a describir ruinas, especialmente de templos, como si el pocta expresara en ellos su nostalgia por un pasado glorioso y de fe firme, que a edificios que ante él se mostraran en toda su integridad $\mathrm{y}$ magnificencia.

Ocho le las más características leyendas tienen como escenario principal te su acción unas ruinas solitarias, desiertas, sombrias y misteriosas, tristes o melancólicas, por entre cuyas hendiduras crece el musgo, la hiedra, los jaramagos, las ortigas y los zarzales, y en las que se escuclian los susurros del viento, los graznidos de las aves y el rumor producido por los reptiles al deslizarse fugitivos. Una de ellas es, como hemos visto, La rosa de pasión. Las otras son: El rajo de lima:

1... aún quedaban en pic los restos de los anclıos torreones de sus muros, aún se veian, como en parte se ven hoy, cubiertos de hichla y campanillas blancas, los macizos arcos de su claustro, las prolongadas galerias ojivales de sus patios de armas, en las que suspiraba el viento con un gemido agitando las altas hierbas.

Iin los huertos y en los jardines, cuyos senderos no hollaban hacia muchos años las plantas de los religiosos, la vegetación, abandonada a si misma, desplegaba todas sus galas, sin temor de que la mano del hombre la mutilase, creyendo enbellecerla. I,as plantas trepadoras subian encaranándose por los añosos troncos de los árboles; las sombrias calles de álamos, cuyas copas se tocaban y se confundian entre si, se habian cubierto de césperl; los cardos silvestres y las ortigas brotaban en medio de los enarenados caminos, $y$ en los trozos de fábrica, próximos a desplomarse, el jaramago, flotando al viento como el penacho de una cimera, y las campanillas blancas y azules, balanceindose conno en un columpio sobre sus largos y flexibles tallos, pregonaban la victoria de la destrucción y la ruinan ${ }^{2}$.

1 Ibial., 11). $252-2.53$.

IIbid., 1). 136-137. 


\section{La cruz del diablo:}

-Aún testifican la verdad de mi relación algunas informes ruinas que, cubiertas de jaramago y musgo, se alcanzan a ver snbre su cumbre desde el camino que conduce a este pueblo' ${ }^{1}$.

IIil tiempo pasú; comenzaron los zarzales a rastrear por los desiertos patios, la hicdra a enredarse en los oscuros manchones y las campanillas azules a mecerse colgadas de las mismas alunenas. Los desiguales soplos de la brisa, el grazuido de las aves nocturnas y el numor de los reptiles que se deslizaban entre las altas hierbas, turbaban sólo de vez en cuando el silencio de muerte de aquel lugar maldecido; los insepultos huesos de sus antiguos moradores blanciueaban al rayo de luna, y aín podía verse el liaz de armas del señor del Segre colgado del negro pilar de la sala del festin" ${ }^{2}$.

\section{Tres fechas:}

"lin su clave hay un escudo, roto ya y carcomido por la acción de los años, en el cual crece la hiedra, que, agitada con el aire, flota sobre el casco que lo corona como un penacho de plumis.

Debajo de la bóveda y enclavado en el nuro se ve un retablo con su lichzo ennegrecido e imposible de descifrar, su marco dorado y cluurrigueresco, su farolillo pendicnte de un cordel y sus votos de cera.

Más allá de este arco que baña con su sombra aquel lugar, dándole un tinte de misterio $y$ tristeza indescriptible, se prolongan a ambos lados dos hileras de casas oscuras, desiguales y extrañas, cada cual de su forma, sus dimensiones y su colorn ${ }^{3}$.

"()tro frente lo constituia un pareclón negruzco, lleno de grietas y hendiduras, en donde algunos reptiles asomaban su cabeza de ojos pequeños y brillantes por entre las hojas de nusgo; un paredón altísimo, formado de gruesos sillares, sembrado de huecos de puertas y balcones, tapiados con piedras y argamasa, y a uno de cuyos extremos se unia, formando ángulo con él, una tapia de ladrillos, desconchada y llena de mechinales, manchada a trechos de tintas rojas, verdes o amarillentas, $y$ coronadas de un bardal de heno seco, entre el cual corrian algumos tallos de enredaderas" ".

\section{El Crislo de la Calavera:}

"Un arco reliundido en el muro, en el fondo del cual se veía la iuragen del Redentor enclavado en la cruz y con una calavera al pic; un tosco cobertizo de tablas que lo defendia de la intemperie y el pequeño farolillo colgado de una cuerda que lo iluminaba débilmente, vacilando al impulso del aire, formaban todo el reta-

\footnotetext{
1 Ibid., p. 153.

2 Ibid., 1. 157.

- Ibial., pp. 175-176.

- Ibid., p. Is3.
} 
blo, alrededor del cual colgaban algunos festones de hiedra que hablan crecido entre los oscuros y rotos sillares, formando una especie de pabellón de verdurav 1.

\section{El beso:}

-.. la iglesia estaba completamente desmantelada; en el altar mayor pendlan aún de las altas cornisas los rotos jirones del velo con que le hablan cubierto los religiosos al abandonar aquel recinto; diseminados por las naves veianse algunos retablos adosados al muro, sin imágenes en las liornacimas; en el coro se dibujabau con un ribete de luz los extraños perfiles de la oscura sillerla de alerce; en el pavimento, destrozado en varios puntos, distinguianse aún auchas losas scpulcrales llenas de timbres, cscudos y largas inscripciones góticas; y allá a lo lejos, en el fondo de las silenciosas capillas y a lo largo del crucero, se destacaban confusamente entre la oscuridad, scmejantes a blancos e inmóviles fantasmas, las estatuas de piedra que, unas tendiclas, otras de hinojos sobre cl mármol de sus tumbas, parecian ser los únicos habitantes del ruinoso edificion" ${ }^{2}$.

\section{La cueva de la mora:}

"De los muros no quedan mis que algmos ruinosos vestigios; las piedras de la atalaya han caidlo unas sobre otras al foso, y lo lian cegado por completo; eu el patio de armas crecen zarzales y matas de jaramago; por todas partes a donde se vuelven los ojos no se vell más que arcos rotos, sillares oscuros y carcomidos, aqui un lienzo de barbacana, entre cuyas hendiduras nace la hiedra; all un torreón que aún se tiene en pie como por milagro; más allá los postes de argamasa. cou las anillas de hicrro que sostenian el puente colgante" ${ }^{3}$.

\section{El Miscrere:}

"Ias gotas de agua que se filtraban por entre las grictas de los rotos arcos y caían sobre las losas con un rumor acompasado, como el de la péndola de un reloj; los gritos del bulı, que graznaba refugiado debajo del wimbo de piedra de una imagen, de pie aún en el lueco de un muro; cl ruido de los reptiles que, despiertos de su letargo por la tempestad, sacaban sus disformes cabezas de los agujeros donde duernen o se arrastraban por entre los jaramagos y los zarzales que crecian al pie del altar, entre las junturas de las lápidas sepulcrales que formaban el pavinento de la iglesia; todos esos extraños y misteriosos murmullos del campo, de la soledad y de la noche llegaban perceptibles al oido del romero, que, sentado sobre la mutilada estatua de una tumba, aguardaba ansioso la hora en que hubiera de realizarse el prodigion".

1 Ibid., p. 212.

I Ibid., p. 292.

s Ibid., p. $32 \mathrm{I}$.

- Ibid., p. 359. V. también Cartas desde mi celda, Carla primera, O. C. T. II, página 9. 
Sin llegar a ostentar el papel de escenario de la trama, también hay ruinas en Creed en Dios:

-... se dirigió al castillo, a cuyas puertas llegó cuando apenas clareaba el dla. Iil foso estaba cegado con los sillares de las derruidas almenas; el puente levadizo, inítil ya, se pudrla colgado aín de sus fuertes tirantes de hierro, cubiertos de orin por la acción de los años; en la torre del homenaje tañia lentamente una cam. pana; frente al arco principal de la fortaleza y sobre un pedestal de grauito se elevaba una cruz; en los muros no se vela un solo soldado; $y$, confuso y sordo, parecla que de su seno se elevaba como un murmullo lejano, un himno religloso, grave, solemue y magnifico" 1 .

$\mathrm{Y}$ aunque no propiamente ruinas, algo de marchito y arruina do puede contemplarse también en la segunda visión, ya transcrita, del ventorrillo en La Venta de los gatos; en el ábside solitario de La mujer de piedra $^{2}$, y en la visión fantasmagórica de la catedral en La ajorca de oro $^{3}$.

\section{Ejomplo de paisaje solidario}

¿Razones de esta preferencia? Tres se nos ocurren. La primera es la actitud, típicamente romántica, de Bécquer ante el paisaje. La segunda, su postura ante el dilema tradición-civilización ". La tercera, muy especialmente becqueriana, su gusto por lo pintoresco, es decir, por todo aquello que mereciera ser pintado y, como dice Ramírez Araujo, (la ruina - mejor si se trata de un vestigio monumental - tiene, en efecto, la cualidad de ser pintoresca, es decir, apta para ser pintada o dibujadai) 5 .

La ruina, a fin de cuentas, no significa otra cosa, como apunta DíazPlaja, "que el predominio de lo natural sobre lo artificial" ${ }^{\circ}$ y esto, para el romántico, tiene indudablemente el profundo sentido de venganza que le atribuye Simmel ?, pero tanbién un sentido de relación

1 O. C. T. I, p. 272.

2 O.C., T. II, p. 337 y ss.

s $O$. C., T. I, p. 74 y ss.

- V. sobre este problema nuestro articulo Bécquer, Sevilla y el progreso, en $A B C$. Sevilla, 13 de diciembre de 1969.

- V. Aliljandro Ramírez ARAUjo, Bécquer y la reconstrucción del pasado, Hispania. Waslington, 1956, XXXIX, p. 314.

- GuIr,II:RMo DfAz-PI,AJA, Introducción al estudio del romanticismo español. Madrid, Espasa-Calpe, 19ł2, p. 1 i 8.

7 Para simmis, en la ruina se ha roto al fin la exacta compensación entre la uaturaleza y el espíritu -representada por el edificio-, a favor le la natura- 
sentimental entre la trama y el escenario, entre el espíritu del autor y el paisaje.

El paisaje, en la obra de Bécquer, no es jamás un escenario estático. Por el contrario, se solidariza siempre con el autor o con la trama, lo que, a fin de cuentas, viene a ser lo mismo. A veces, hasta el punto de representar un papel activo: "Y todo callaba a su alrededor y parecía respetar su pena.... 1

Aunque no falta la descripción de lugares deliciosos; de algún paisaje diurno, si no alegre, al menos tranquilo y luminoso ${ }^{2}$; de algún nocturno sereno y perfumado, de luna clara, alto silencio y soledad solemne ${ }^{3}$, lo que abunda en los escenarios de las leyendas son los laberintos de callejas estrechas, oscuras y tortuosas, sombrias, silenciosas y solitarias, en las que apenas se oyen ladridos lejanos, rumores de voces, susurros del viento 4; los crepúsculos melancólicos, tristes, cuando no henchidos y amcnazantes ${ }^{5}$, los nocturnos oscurísimos lóbregos, anubarrados o lluviosos, con aullidos del vicnto, chirridos, rumores confusos, sonidos misteriosos, ladridos, lejanas voces ${ }^{\circ}$.

$\Lambda$ tendiendo a las relaciones del paisaje con el espíritu del protagonista, Díaz-Plaja observa unas alternancias en su valoración a partir del Renacimiento. Al paisaje independiente del espíritu del poeta lo denomina "paisaje impasible" y lo encuentra en las obras del Renacimiento, el Neoclasicismo y el Naturalismo; al que se presenta como una proyección o fusión de dicho espiritu, "paisaje solidario" y lo halla

leza. "Este desplazamiento del fiel se resuelve en una tragedia cósuica, que en. vuelve, a nuestros ojos, toda ruina en las sombras de la melancolla; porque entonces la destrucción de la obra arquitectónica aparece como la venganza que toma la naturaleza contra la violencia que le hizo el espiritu cuando la moldeó y conformó a su imagen y semejanza" (V. Cullura femenina. Madrid, Revista de Occidente, 1934, p. 212. Cit. por DfAz-PI, JA en el lugar indicado en la nota anterior.)

1 Cir. La promesa, O. C., T. I, p. 274.

2 Cir. La corza blanca, Ibid., pp. 217-233; Los ojos verdes, Ibid., p. 6r.

3 Cfr. El rayo de luna, Ibid., pp. I37-145; La corza blanca, Ibid., p. 238; El gnomo, Ilid., p. 344 .

- Cfr. El rayo de luna, Ibid., p. I40; El Cristo de la calavera, Ibid., p. 209; La rosa de pasibn, Ibid., p. 244; El gnomo, Ibid., p. 339; Tres fechas, Ibid., pp. I75. I 81 y ss. y 189 y ss.; La mitjer de piedra, $O$. C, T. II, p. 336.

- Cfr. Tres fechas, O. C., 'T. I, pp. I79, 186, I89 y 190; La Venta de los gatos, Ibid., p1. 377, 384 y 385; El gnomo, Ibid., p. 334; La ajorca de oro, Ibid., p. 68; Las hojas secas, Ibid., p. 367; La voz del silencio, O. C., T. II, p. 4I2.

- Cír. La cruz del diablo, O. C., 'T. I. p. 156; La rosa de pasión. Ibid., p. 250; El beso, Ibid., p. 3or; Crecd en Dios, Ibid., pp. 270-27I; El Miserere, IUid., pp. 353 y 358-359; Los ojos verdes, Ibid., p. 66; La Venta de los galos, Ibid., p. 338. 
en el Barroco, en el Romanticismo y en la Nueva Poesía ${ }^{1}$. Por romántico retardado o por precursor de la nueva poesía, el de Bécquer es una muestra cabal de paisaje solidario.

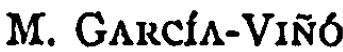

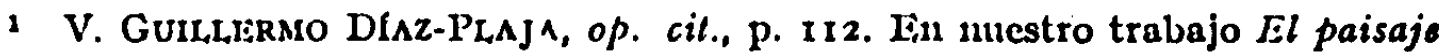
podtico de Antonio Machado (Archivo Hispalense, núm. 77, 1956, pp. 259-273. intentamos nosotros establecer una distinción del paisaje solidario, segúu actuara éste como instrumento de la expresión del sentimiento o como evocador del sentimiento expresado (p. 26.1). Vid. también, MANUEL GaRcha-VIŇ́, Momento actual del paisaje en la pintura, Revista de Ideas Esteticas, núm. 78, abril-mayo-junio, x962. 